\title{
A Study on Training Needs Analysis (TNA) Process among Manufacturing Companies Registered with Pembangunan Sumber Manusia Berhad (PSMB) at Bayan Lepas Area, Penang, Malaysia
}

\author{
Mohd. Anuar bin Arshad1 \\ Ahmad Nasir bin Mohamad Yusof² \\ Arshad Mahmood ${ }^{3}$ \\ Adeel Ahmed 4 \\ Sohail Akhtar 5 \\ School of Management, Universiti Sains Malaysia, Penang 1,2,3,4 \\ First Solar Sdn Bhd, Kulim Hi-Tech Park, Kedah² \\ University of Turbat, Pakistan 4 \\ Main Author: anuar_arshad@usm.my; Corresponding Author: arshadchat@gmail.com
}

Doi:10.5901/mjss.2015.v6n4s3p670

\begin{abstract}
Employees are said to be the most valuable asset in an organisation (Ferdinand, 1988). Therefore, employees talent need to continuously develop and nurture in achieving the highest performance of the organisation. Bentley (1994) emphasized the key to finding and developing the talent is by training whereby training is a planned effort of the organisation to facilitate employee knowledge and skills that are critical for successful job performance (Noe, Hollenbeck, Gehart and Wright, 2008). Thus, any training intervention must be preceded with the process of training needs analysis (TNA). This prerequisite steps is considered important in providing organisation with valuable information to help them in designing and implementing strategic training programs, that will lead to organisational sustainability. The manner to which TNA process is approached are also important in determining the accuracy of it's result. This study is to understand how far an organisation is adopting the recommended practices in TNA process. The data was collected using a set of questionnaire. The questinnaires were distributed to 236 companies resulting $40.10 \%$ of return rate. The findings showed that organisation do recognise the importance of proper training needs in helping to design an effective annual training plan. There is no difference among the organisations on the way TNA is conducted. The study result also offers practical understanding to human resource and training practitioners on how organisations implement their TNA. Besides that, this study provides a knowledge on how TNA should be conducted and the variables that affect its effectiveness. Futher, the study result can be used by other organisation to improve their current TNA process to design impactful training program for the organisation sustainability.
\end{abstract}

Keywords: Training Need Analysis (TNA), sustainability, training, manufacturing, Penang

\section{Introduction}

To train employees effectively is not an easy task. From training is an investment and its not viewed as a cost by human capital theory (Bliss, 2014). Research acclaimed the importance of training by which organization can be develop and enhance organization profitability (Sung et al, 2014; Tharenou, 1991). Tung-Chun (2001) also agreed that educated and well-trained employees are a pre-requisite for an organisation to facilitate employee knowledge and skills that are critical for successful job performance (Noe, Hollenbeck, Gerhart, and Wright, 2008).

Some factors that Human Resource and Training practitioners must be careful while designing or proposing training programs (Fleck 2014). These factors will determine if the transfer of learning actually take place. One of the very important factors are the process of Training Needs Analysis (TNA) (Conger, 2015). It is the condition by which training would make effective and approachable in the start.furthermore, it includes attentive consideration towards the accuracy of the recognized "need" and the fulfillment of these "need".If these "needs" are correctly recognized while using right process, then the probability of success of the training is high.Training must be approached systematically in order to enjoy the benefits on training investment. 
The organization required some steps to manage the training process. The steps start with identification regarding training need, designing and also developing suitable training solution, implementing this training and evaluating the training programs effectiveness whether the original needs have been achieved. These steps are popularly known as the "training cycle" and many training researches agreed that these steps are necessary to ensure training effectiveness (Leat and Lovell, 1997).

Among the steps in the training cycle is the identification of training needs. Training need analysis (TNA) can be considered the most important steps in ensuring the effectiveness of the overall training process. This statement is made based on the emphasized placed by many training theorist on this step, who agreed that TNA must precede any type of training intervention (Wright and Geroy, 1992; Anderson, 1999). This opinion also shared by Elbadri (2001) which stated that in the begining stage of the training cycle, TNA minimized error achieved by the training programs.these two main isues are examine in the TNA.The first issue is arranged before the implementation of training.The second issue is about manner which is arranged by TNA process.

Although many organizations declare that they arranged TNA,these results and analyses which is utilize to prepare the Annual Training Plan (ATP), It would not be effective if organizations did not approach them accordingly (Bowman and Wilson, 2008). According to (Wagonhurst, 2002, pg. 78) "inadequate needs assessment can result in inappropriate and inefficient interventions which could either have no impact or have a deleterious impact on the actual performance problem".

\section{Literature Review}

Employees are consider to be the most important asset for every organzations,Moreover these organizations are only as better as their employees (Csath,2009; Zhang 2014;Ferdinand, 1988), further pointed out that only through people organization can achieve sustainablity. Hence,this is important for the organization to take control on Knowledge skills,attitude of the employees to sustain competitive and organization success.the proper method needs in the training programe to improve and obtain employee's knowledge and skills in the organization (Bently 1994) further emphasize that the key to finding and developing the talent is by training. In general, training refers to a planned effort by an organization to facilitate employee knowledge and skills that are critical for successful job performance (Noe, Hollenbeck, Gerhart and Wright, 2008). Organization has been investing into training because they believe that it is a good thing to do. To take benefits from the training investment, It is necessary that training must be proceed accordingly (Daniels, 2003).

\subsection{The Importance of Training Needs Analysis}

Systematic approach means the training process has at least four phases. These phases begin with needs analysis, designing of the training and relevent training solution,delivering and evaluating on the training programe effectiveness whether the objectives have been achieved. These steps are popularly known as the "training cycle" and many training researches agree these steps are necessary to ensure training effectiveness (Daniels, 2003; Leat and Lovell, 1997; Wilson and Bowman, 2008; Lorento and Gomez, 2004; and, Reed and Vokala, 2006). The four phases in the "training cycle' are: 1. Evaluate Training, 2. Identify Training Needs, 3. Plan, 4. Implement Training (Balderson, 1999).

Among the phases in the training cycle, the identification of training needs or training need analysis (TNA) can be considered the most important phase in ensuring the effectiveness of the overall training process.

The well-known theorists emphasiszed on the training and argue that TNA must come first before any other training intervention (Wright and Geroy, 1992; Anderson, 1999). This opinion also shared by Elbadri (2001), which stated that as the first stage in the training cycle and strongly believed that TNA should minimizes error possibly made in the training programs. (Jointly phases in the training cycle are identification of training needs or training need analysis (TNA) that can be taken the significant phase and to be ensured the effectiveness of overall training process. In this phase various training theorists' statements which are based on the emphasized are placed.

\subsection{The Concept of Training Needs Analysis}

There are few terms that can be used to refer to the process of identification of training needs. The most common terms are training needs analysis (TNA). Reed and Vokala (2006), defines the term training needs analysis as a process of gathering, assessing and analyzing data to determine the training needs for an organization. A more details meaning of TNA explained by Chiu, Thompson, Mak, and Lo (1997, pg 87) as "an ongoing process of gathering data to determine 
what training needs exist so that training can be developed to help the organization accomplish its objective". In fact, TNA refers to an effort wherein the data is systematically gathered for analysis and solving issues concerned in the performance by evaluating the potential training activities (Bucalo, 1984; Bowman and Wilson, 2006). Research reveals that training cannot solely treat all performances. Knowledge and necessary skills are not the only reasons concerned with Employee inability to perform well, but it is due to non-training issues. However, Chiu, et al (1999) insist that performance' problems concerned with lack of knowledge and important skills can only be solved by training. (Goldstoin, 2014) Training can solve employees performance problem only if the problem are due to the employee lack of knowledge and skills as emphasized by Chiu, et al (1999)

\subsection{Approcahes in Training Needs Analysis}

There are two main approaches are discuss with regards to training needs analysis. The first approach is categorized as reactive approach which is more focusing on current performance gap in indoviduals. The second approach which is more forward looking is categorized as proactive approach.

\subsubsection{Reactive Approach}

Anderson (1994) stresses that reactive approach taken up extensive criticism and fails in linking the employees training needs with strategic objectives of an organization. The organizational events that react to the growing performance gaps on present needs are not appropriate in a business world accustomed with rapid mobility.

Thefuture needs and requirements perceived as crucial and fundamental logic in maintaining the survival and competitiveness of organization, are seriously not considered. Furthermore, the major problem identified with consistent attention on job performance gap is the extensive confusion and irrelevancy concerning the concepts of 'job'(Anderson (1994). He stresses further that while, by the time, the identified needs being translated, in order to convert it into training program and deliver to the employees necessitating such need, the context and capacity of needs and the content were already no longer in fashion and had lost their influence.

\subsubsection{Proactive Approach}

Due to some weakness in reactive approach, a new approach of TNA which are excessively proactive has acquired more popularity (Wright and Geroy, 1992; Berger, 1993; Wilson and Bowman, 2008; Hyland and Zheng, 2007; Daniels, 2003; and Anderson, 1994). The approach iniated with the idea of inspecting business environment wherein major senior managers were questioned about judgement of their organizational environment and its current and future's five years entended stability. Firstly, the team of senior management were keenly required with their cooperation and participation in order to find out the and arrangements of different componenets of their organization. Furthermore, the final step deals with the determiniation of the knowledge, skills and attitude required in respect to the important changes taking place in the organization.

Berger (1993), acknowleged the better importance of this approach than the traditional approach to TNA. Because, this approach unearthed the contribution at sub-units as how these take part in the overall organization. Finally, this approach resulted excessisively future-oriented and responsive needs.Anderson (1994), whom very supportive of this approach explained that training must be percieved as a positive process which anticipates trends and future changes. According to Anderson (1994, pg. 24), "a proactive approach unlike the deficit models, will actively seel out ways to help people further develop existing strengths and encourage them to improve both the quality of their contribution to the organization and their life at work". According to Wright and Geroy (1992), the ability to predict training needs is of paramount importance if training is to make a larger contribution to productivity.

\subsection{Training Needs Analysis Model}

One of the earliest and most classical works to influence TNA and the field of training and development was written by McGehe and Thayer (1961) and Goldstein (1998). McGehe and Thayer (1961) introduced the tripartite level of the TNA model and this model has been a great influence to other subsequent models of TNA. The three levels are: 1. Organizational Analysis; 2. Operational Analysis; and 3. Individual Analysis. 


\subsubsection{Organizational Analysis}

Organizational analysis involve a process of determining at where within the organization training emphases could and should be placed (Ling et al 2014; McGehe and Thayer, 1961). In addition, Noe et al (2009) explained that organization analysis involved the consideration of organization strategic direction; such as analyzing the organization mission, vision and values and then determining relevant training needs to support those statements.

\subsubsection{Operational Analysis}

According to McGehe and Thayer (1961) operation analysis involve the process of determining the contents of training should be in for an employee to perform a task or job in an effective and efficient way (Ferreira et al 2015). While, Daniel (2003) referred operation analysis as job or task analysis. Hence, Noe et al (2009) explained task analysis is a process of identifying the job knowledge, skills and attitude that need to be emphasized in training.

\subsubsection{Individual Analysis}

Individual analysis also known as person analysis. Noe et al (2008) explained that person analysis helps identify who needs training based on performance deficiencies that result from lack of knowledge, skills or attitude (Martin,2014). In addition, Leat and Lovell (1997) strongly stated that person analysis process should not only consider current training needs, but also should identify training and development strategies that will help the individual to achieve expected performance standards that are important to the organizational goals. For instance, Daniels (2003) believed that employees working in team required different training needs as compared to individual working alone.

\subsection{Key Variables factors in TNA Process}

There are five main variables that had been given most priority in ensuring TNA effectiveness. The five variables are: 1. Approach in Managing Training Function; 2. Methods of Data Gathering; 3. Level of Analysis in TNA Process; 4. Strategic Alignment with Organizational Strategy; and 5. Involvement of Stakeholder.

\subsubsection{Approach in Managing Training Function}

According to Elbadri (2001), most training theorist and practitioners agreed that systematic training processed has four steps or phases; assessment or analysis, design and development, delivery or implementation and evaluation.Thus, McClelland (1993) explained that organization that adopting all four phases in managing their training function has and advantage to revise and monitor the outcome from each phase.

\subsubsection{Methods of Data Gathering}

Methods of data collection refer to the instrument that analyst can use to collect data for conducting TNA (Anderson, 1994). Generally, TNA method can be divided into two broad categories which is Qualitative and Quantitative method. Quantitative data generally preferred by organization as it provides hard evidence regarding training needs (Daniel, 2003). Qualitative on the other hand, emphasizes the 'soft' data, for instance, interviews, focus group discussion, observation, brainstorming and assessment centres. According to Mc Clelland (1993), qualitative data normally used when analyst need to explore more in detail the data discovered quantitatively. However, Waganhun (2002) emphasized that TNA are advised to include both quantitative and qualitative data to yield the most successful and reliable results.

\subsubsection{Level of Analysis in TNA Process}

According to McGehe and Thayer (1961), by including multiple level of analysis will yield better TNA results.

\subsubsection{Strategic Allignment with Organizational Strategy}

TNA is conducted to improve organization performance through helping people to acquire the necessary knowledge, skills and attitude (Wright and Geroy, 1992). Therefore, Ferdinard (1988), described TNA as a process of acquiring and 
developing people skills to meet the business objectives and it has to be conducted in a holistic way. Besides that the TNA results should be able to capture future efficiencies and align closely with organization operations and strategies (Chiu et al, 1999; Johnson, 1993).

\subsubsection{Involvement of Key Stakeholder}

According to Elbadri (2001) there are needs to gain more involvement and support from top management and other key stakeholder in training process in order to achieve best results. On top of that Tharenou (1997), Johnson (1993) and Wills (1994) added TNA should not delegated heavily to HR and traning personnel because managing director, heads of departments, supervisors and human resource manager are all important stakeholder in the training process.

\section{Methodology}

This study opted a quantitative method since this study is descriptive resaerch where it is undertaken to ascertain and describe the variables that lead to training need analysis process effectively. The data gathered through a questionnaire survey on the 236 companies in Bayan Lepas Industrial Area as listed in the directory listing of Human Resource Development Corporation(HRDC), 2008.

\subsection{Sampel}

The population of this study comprised of organisation with total employees more than 100 which is located at Bayan Lepas Industrial Area and registered with HRDC. These registered organisations are compulsory to make monthly levy payment to the Human Resource Development Fund (HRDF) managed by HRDC mainly to fund their future training cost. Therefore, these organization will actively utilize their levy by sending their employee for training.

\subsection{Procedure}

Primary data were collected through questionnaire distributed to the HR or Training Manager of the organizations. The main target of the respondent were the person in-charge of training function. There were 236 questionnaires distributed, 108 questionnaires were returned and 11 were rejected due to incomplete information. Therefore, useable questionnaires were 97 comprising 41.10 percent of response rate.

Quantitative research data primarily involves statistical analysis involving the process of data editing, coding and entering before the data being analysed (Zikmund, 2000). As for this study, data collected were analysed using the Statistical Package for Social Sciences (SPSS) version 16.0 in three stages which are: 1. Descriptive analysis; 2. Factor Analysis; and 3. Regression Analysis.

\section{Results}

\subsection{Respondents' and Organizations' Profile}

Majority of the respondents are Executives and Managers (92.8\%) with most of them have 2-5 years of working experience (99.0\%) and 71.1 percent possessed right qualification (HRM and TD). Majority of them (83.5\%) attended the TNA program and 80.4 percent having intermediate and advance knowledge in the TNA. On the aspect of the organizations which were participated in this study, 90.7 percent were from the manufacturing industry, with 72.2 percent were foreign company which 79.2 percent of the company having between 100-1000 employees. Majority of the organizations had operated their business for more than 6 years (88.7\%) and set up separate unit and staff for training section or department (70.1\%) together with clear policies and procedures on TNA (87.6\%).

\subsection{Descriptive and Correlation Statistical Analysis}

Descriptive statistics of all variables (refer to Table 1.0) showed that TNA alignment with organization strategy and level of analysis has the highest standard deviation (.93) and (.84). While the correlation test (refer to Table 2.0) showed that systematic approach in managing training function are highly and positively correlated with alignment with organization stratgey $(r=.82)$ and perception towards TNA was the least compare to all other variables (systematic approach, $r=.14$; 
alignment with organization strategy, $r=.23$; level of analysis, $r=.00$; data gathering method, $r=.28$; and involvement of key stakeholders, $r=.22$ ).

Table 1.0. Descriptive Analysis

\begin{tabular}{|c|l|c|c|c|c|}
\hline No & Variables & Min & Max & Mean & SD \\
\hline 1. & Perception on TNA & 3.00 & 5.00 & 4.30 & .48 \\
\hline 2. & Approach in Managing Training Function & 2.00 & 5.00 & 3.87 & .67 \\
\hline 3. & Alignment TNA with Strategy & 1.00 & 5.00 & 3.65 & .93 \\
\hline 4. & Level of Analysis & 1.00 & 5.00 & 3.64 & .84 \\
\hline 5. & Data Gathering Method & 1.67 & 4.33 & 2.84 & .70 \\
\hline 6. & Involvement of Key Stakeholder & 2.00 & 4.97 & 3.33 & .46 \\
\hline 7. & Types of Organization Sector & 1.00 & 3.00 & 1.10 & .34 \\
\hline 8. & Ownership & 1.00 & 2.00 & 1.72 & .45 \\
\hline 9. & Number of Employees & 2.00 & 4.00 & 2.80 & .76 \\
\hline 10. & Years of Operation & 1.00 & 4.00 & 3.49 & .72 \\
\hline 11. & Independent Training Unit & 1.00 & 2.00 & 1.29 & .46 \\
\hline 12. & Establishment of TNA procedures and policies & 1.00 & 2.00 & 1.12 & .33 \\
\hline
\end{tabular}

Note: $\mathrm{SD}=$ Standard Deviation

Table 2.0. Pearson Correlation Analysis

\begin{tabular}{|l|c|c|c|c|c|c|}
\hline & $\begin{array}{c}\text { Perception } \\
\text { towards TNA }\end{array}$ & $\begin{array}{c}\text { Systematic } \\
\text { Approach }\end{array}$ & $\begin{array}{c}\text { Alignment with } \\
\text { Organization Strategy }\end{array}$ & $\begin{array}{c}\text { Level of } \\
\text { Analysis }\end{array}$ & $\begin{array}{c}\text { Data Gathering } \\
\text { Method }\end{array}$ & $\begin{array}{c}\text { Involvement of } \\
\text { Key Stakeholder }\end{array}$ \\
\hline Perception towards TNA & 1 & & & & & \\
\hline Systematic Approach & .143 & 1 & & & & \\
\hline Alignment with Organization Strategy & $.234^{\star}$ & $.823^{\star *}$ & 1 & & & \\
\hline Level of Analysis & .009 & $.735^{\star *}$ & $.743^{\star *}$ & 1 & & \\
\hline Data Gathering Method & $.274^{* *}$ & $.668^{* \star}$ & $.730^{* *}$ & $.696^{* *}$ & 1 & \\
\hline Involvement of Key Stakeholder & $.216^{*}$ & $.556^{* *}$ & $.547^{* *}$ & $.660^{* *}$ & $.607^{* *}$ & 1 \\
\hline
\end{tabular}

Note: . ${ }^{*}$ correlation is significant at the 0.05 level (2-tailed); .* correlation is significant at the 0.01 level (2-tailed)

\subsection{Regression Analysis}

Regression analysis was conducted to test the hypothesis. There are six hypotheses has been tested and below are the summary of the results (Table 3.0).

Table 3.0. Summary of the Hypotheses Testing

\begin{tabular}{|l|l|l|}
\hline No & Hypotheses & Conclusion \\
\hline H1 & The organization sector will positively influence the proper conduct of Training Needs Analysis in the organization. & Rejected \\
\hline H2 & The organization ownership will positively influence the proper conduct of Training Needs Analysis in the organization. & Accepted \\
\hline H3 & The number of employees in the organization will positively influence the proper conduct of Training needs Analysis in the organization & Accepted \\
\hline H4 & The organization operation period will positively influence the proper conduct of Training Needs Analysis in the organization. & Accepted \\
\hline H5 & The existence of independent training unit will positively influence the proper conduct of Training Needs Analysis in the organization. & Accepted \\
\hline H6 & The establishment of TNA procedure and policies will positivelyinfluence the proper conduct of Training Needs Analysis in the organization & Accepted \\
\hline
\end{tabular}

\section{Discussion}

The environment in which business operate today has changed dramatically compared to few decades ago. More companies are begins to realize that one way to ensure their business remain competitive is by constantly increasing the value of their people by improving their knowledge, skills and attitude. In order to do this, business should not only react when problem occurs, rather they should be more proactive, think what they must possess in the future and be well prepared over their competitors. Training should focus on building individual and organizational capability so that it gives the organization the sustainable competitive advantage through training activities, whereby a proper Training Needs Analysis (TNA) should be conducted (Ferreira et al 2015; Anderson, 1999; Bowman and Wilson, 2008; Wagonhurst, 2002; and Elbadri,2001).

Therefore, organizational training strategies must be aligned with organizational strategies to achieve greatest benefit in term of performance improvement. There was evidence that training conducted in organizations was often not 
aligned with organization strategy, as the training needs were not properly assessed to determined how such needs contributed to the overall achivements of organization strategic objectives (O'Driscoll and Taylor, 1992). Correctly identified training and development needs of the organization will assit in the alignment of training with the organization stratergy.

Literature review revealed that in order to conduct a proper TNA, an organization should incorporated all the three variables in TNA such as systematic approach in managing training functions, using various data gathering methods, conducting needs analysis at four diffent levels and direct involvment of key stakeholder. This study have supported the fact whereby almost all organizations considered conducted proper training needs analysis in their organization before generating annual training plan.

Needs analysis is viewed as a process in which the training needs of both the employees and the organizations are identified to address the gap between employees abilities and performance, and the organization's requirements. Hence, the four levels of identification which are: 1. Organization's level; 2. Department's level; 3. Individual's level; and 4. Employee's level were examined. The frequency results showed that more than eighty percent (80\%) of the organizations analysed the four levels. This study also found that the propotion of analysis done at the organizational level is the highest. Therefore the study finding supported the literature review suggestion that organizational needs must be analysed first before looking on the needs of other levels. This finding concluded that current trend of TNA is concentrating on the business effectiveness instead of personnal effectiveness. As mentioned by Chiu et al (1999, pg. 86), "the danger that if it moves too far away from the individual needs to the business bottom-line issues, in the long run, a demoralised workforce will hinder the growth of the organization". Hence, it is a need to balance the needs of organization and individual's need.

In reference of data gathering method, the study showed that questionnaire survey, performance appraisal forms, performance document review and brainstorming session were most frequently utilized by organization in identifying training needs. This findings found inline with the previous research conducted by Brown (2002). Amongst the method, questionnaire survey was found the most popular and applied by the organization (70\%) although it is known as a traditional method.

Besides that this study found that organization did recognized the importance of proper TNA in helping them to come out with effective ATP whereby eighty five percent (85\%) of the organization admitted that their ATP was generated from TNA. This findings was found in agreement with Poon and Rozhan (2000) study.

In considering organization strategy when conducting TNA, this study found that majority of the organization at Bayan Lepas area agreed that aligning organization strategy with training strategy was important. Therefore, this study concluded that the consideration onto organization key business stratgey such as mission, vision, objectives, and business plan taken into account of TNA operation. This amplifies literature review findings that identifying training needs are part of organization strategic process (Anderson, 1994; Horwitz, 1999).

On the aspect of contextual factors of this study which are type of sector, ownership, number of employees, years of operation, presence of independence training unit and establishment of TNA procedure and policies have been also tested on the proper conduct of TNA.

It was found that type of organization sector has not revealed positive influence to the proper conduct of TNA and it signified that there is no effect on how TNA is conducted in the organization in relation to the organization sector.

However, an ownership showed significant positive relation to the proper conduct of TNA in the organization. This finding was supported by Zheng and Hyland (2007) that multinational companies are more advanced in managing and providing training prgrams and in this study showed that seventy two percent (72\%) of the respondents were an international companies.

In term of employees capacity, the result also showed there is positive influence to the proper conduct of TNA. The data showed that around eighty percent (80\%) of the respondents possessed between 100-1000 employees and it seems to contradict with Lynch and Black (1995) findings that smaller organization tends to focus less on training than the larger organizations.

Organization year of operation has no significant influence to the proper conduct of TNA in the organization. This results supported by the fact that around seventy one percent (71\%) of the respondents were qualified in the area of HRM and TD and around eighty three (83.5\%) had attended the TNA training therefore the person in-charge will be able to conduct a proper TNA irrespective of age of the organization.

Meanwhile, the presence of independent training unit has very high influence in relation to the proper conduct of TNA in organization. Conducting proper TNA is a complex task required some level of relevant expertise. Therefore, it can be concluded that the establishment of independent training unit will positively contribute to the proper conduct of TNA and be able to generate effective ATP in the organization. 
This study also found that the establishment of TNA procedure and policies has very high relation to the proper conduct of TNA. Therefore, in order to come out with effective ATP, there must be well developed procedure and policies pertaining to the TNA operation which will be functioning as a standard guideline to everyone in the organization to ensure the consistency of implementation.

\section{Implication of the Study}

The results of the study have shown the six organization contextual factors that affect TNA process. It is hope that the results can be used by training practitioners for better understanding on the factors that can contribute to the overall TNA process effectiveness. Organization may also use the findings of the study to evaluate their current TNA practices and make necessary adjustment as part of continuous improvement in managing their training function. The effective and the right TNA approaches adopted by organization are expected to improve the performance of their employees which will ultimately lead to improve their organization performance. The results of the study also may assist organization in preparing a more comprehensive and focus Annual Training Plan (ATP).

This study is subjective in nature. Therefore, among the limitation were respondents knowledge in TNA concepts play a great influence in determining the reliability of the findings. The survey instuments utilized in this assessment were based on self-report measures, which means information presented by respondents were relying upon their subjective perceptions.

In addition, this study only examines organization at one particular location in Penang state. Therefore, the results may not be generalized to all organization in Malaysia. Moreover, majority of the organization in this study were from manufacturing background and the finding may not suitable for other industries.

Another limitation was finding similar to previous research conducted in Malaysia as a reference. Most of the previous research in the area of TNA was conducted in the western country.

In the future, it is recommended that this study to be expanded to cover a larger sampling population from different location or states in Malaysia. Organization at Prai Industrial Area can be included in future research to represent better picture of the overall scenario of organization in Penang state.

It would be useful to study other organization those in services industry to test the applicability of the model. In addition, the unit of analysis in this study was the organization as represented by individual. This was done due to the limited time available. A more structured schedule interview questionnaire can be used to survey perceptions on TNA process effectiveness.

\section{Conclusion}

This research substantiated the fact that out of six, five organization contextual variable has a relationship with TNA factors. Even though it is not really an in-depth study, it is significant enough to agree upon that the recommendation made by TNA researchers are followed by organization in this study. The right adoption of TNA process will increase on its effectiveness without wasting time, energy and money in order to achieve the desired performance. Johnson (1993) clearly pointed out that performance improvement is achieved through skilled, knowledgeable and committed workers who want to make their organization successful. Training is becoming increasingly important to success. The organization's investment in its people is the most important investment it makes. Exact needs to meet the goal must be ascertained in terms of each level of organization in order to provide training that contributes to the organization business results. Identifying training needs is not easy; it requires a good understanding of the business and of future developments of the organizations.

Most of the studies on TNA are researched in Western countries. Limited empirical evidence can be obtained in Malaysia, particularly from manufacturing industry. Finally, this study present a modest contribution to empirical research in the area of training and development.

\section{Acknowledgment}

This paper is funded by Institute of Postgraduate Studies Fellowship Scheme Universiti Sains Malaysia, Pulau Pinang, Malaysia. 


\section{References}

Bently, T. (1990). Training - Investing in the future. Industrial Management and Data System, pg. 10- 17.

Berger, M. (1993). A Market-led Training Needs Analysis. Industrial and Commercial Training, Vol. 25, No. 1, pg. 27-30,

Bliss, C. J. (2014). Capital theory and the distribution of income (Vol. 4). Elsevier.

Bucalo, J.P. (1984). "An operational approach to training needs analysis", Training and Development Journal, Vol. 38, No. 12, pg. 80-84

Chiu, W., Thompson, D., Mak, W., and Lo, K. (1999). Re-thinking training needs analysis. Personnel Review, Vol. 28, No. 1/2, pg. 77-90.

Conger, S. (2015). Six sigma and business process management. In Handbook on Business Process Management 1 (pp. 127-146). Springer Berlin Heidelberg.

Csath, M. (2009). A world in crisis? Does learning help to create future opportunities? Development and Learning in Organizations, Vol.23, No. 6, pg. 8-10.

Daniels, S. (2003). Employee training: A Strategic Approach to Better Returns On Investment. The Journal of Business Strategy, Vol. 24, pg. 39-42.

Elbadri, A.N. (2001). Training practices of Polish companies: An appraisal and agenda for improvement. Journal of European Industrial Training, Vol.25/2/3/4, pg.69-79.

Ferdinand, B. (1988). "Management training needs analysis (TNA)", Industrial and Commercial Training, pg. 27-31.

Ferreira, R. R., da Silva Abbad, G., \& Mourão, L. (2015). Training Needs Analysis at Work. The Wiley Blackwell Handbook of the Psychology of Training, Development, and Performance Improvement, 32-49.

Fleck, S. J., \& Kraemer, W. (2014). Designing Resistance Training Programs, 4E. Human Kinetics.

Goldstoin, I. L., \& Buxton, V. M. (2014). Training and human performance. Human Performance and Productivity: Volumes 1, 2, and 3, 135.

Gomez, P.J., and Lorento J.C. (2004). Training practices and organization learning capability. Journal of European Industrial Training, Vol. 28, No., 2/3/4, pg. 234-256.

Horwitz, F.M. (1999). The emergence of strategic training and development: The current state of play. Journal of European Industrial Training, 23 (4-5), pg. 180-190.

Johnson, R. (1993). TQM: Quality Training Practices, ASQC Quality Press, Wisconsin, USA.

Leat, M.J., and Lovell, M.J. (1997). Training needs analysis: weakness in the conventional approach. Journal of European Industrial Training, Vol. 21/4, pg. 143-153.

Ling, L., Qing, T., \& Shen, P. (2014). Can training promote employee organizational commitment? The effect of employability and expectation value.Nankai Business Review International, 5(2), 162-186.

Martin, B. O., Kolomitro, K., \& Lam, T. C. (2014). Training Methods A Review and Analysis. Human Resource Development Review, 13(1), 11-35.

McGehee, W. And Thayer, P.W. (1961). Training in Business and Industry, John Wiley \& Sons Inc., New York.

Noe, R., Hollenbeck, J., Gerhart, B., and Wright, P. (2008). Human Resource Management: Gaining a Competitive Advantage, 6th Ed. Mc Graw Hill Companies Inc., New York.

Human Resource Development Corporation, (2008), Senarai Majikan berdaftar Dengan PSMB, Kuala Lumpur.

Reed, J., and Vokala, M. (2006). What role can a training needs analysis play in organizational change? Journal of Organizational Change Management, Vol. 19, №. 3, pg. 393-407.

Sung, S. Y., \& Choi, J. N. (2014). Do organizations spend wisely on employees? Effects of training and development investments on learning and innovation in organizations. Journal of organizational behavior, 35(3), 393-412.

Tharenou, P. (1991). Managers' training Needs and Preferred training Strategies. Journal of Management Development, Vol. 10, No. 5, pg. 46-59.

Wright, P., and Geroy, G. (1992). Needs Analysis Theory and the Effectiveness of large-scale Governemental-sponsored Training programmes: A Case Study. Journal of Management Development, Vol. 11, No. 5, pg. 16-27.

Wills, M. (1994). Managing the training process: Putting the Basic into Practice. Journal of European Industrial Training, Vol. 18, №. 6, pg. 4-26.

Zheng, C., and Hyland, P. (2007). Training practices of multinational companies in Asia. Journal of European Industrial Training, Vol. 31, No. 6, pg. 472-494.

Zhang, Y. (2014). The Relationships Between Employees and Organizations. InUnderstanding Chinese Firms from Multiple Perspectives (pp. 227-256). Springer Berlin Heidelberg.

Zikmund, W.G. (2000). Business Research Methods, 6th Ed., Harcourt College Publisher, Fort Worth, Texas. 